\title{
The Role of Minimally Invasive Surgery in Gallbladder Carcinoma, is it Time to Change our Approach?
}

Aaron Daniel Pinnola ${ }^{1^{*}}$, Nader Hanna ${ }^{2}$ and Cherif Boutros ${ }^{2}$

${ }^{1}$ Department of Surgery, Grand Strand Medical Center, USA

${ }^{2}$ Division of General and Oncologic Surgery, University of Maryland School of Medicine, Baltimore, USA

\begin{abstract}
The safety and utility of the laparoscopic approach to definitive gallbladder. Within the last 5 years, safely performed laparoscopic extended resections in specialized centers have begun to be published as well. The aim of this review is to revisit the dogma of only open surgical approach for gallbladder cancer. Traditional limitations and restraints of minimally invasive approach are discussed and advance in laparoscopic hepatobiliary surgery is emphasized.
\end{abstract}

Keywords: Gallbladder cancer; Gallbladder Carcinoma; Carcinoma

\section{Introduction}

\section{Current concerns regarding the laparoscopic approach}

The diagnosis of gallbladder cancer is made in two distinct clinical fashions: Preoperatively, those patients who have suspicious lesions found with laboratory work or imaging based on history and physical. And incidental, (most common) those patients in whom diagnosis is made by pathology after laparoscopic cholecystectomy or those with gallbladder features concerning for carcinoma intraoperatively. Due to the relative low incidence of gallbladder cancer and lack of distinct symptoms, gallbladder cancer can be found at advanced stages and diagnosis is still usually made postoperatively [1].

For lesions found incidentally, a laparoscopic approach was thought to be a disadvantage primarily because of increased biliary leak rates, delay in the ability to perform an unexpected extended resection, and port site metastasis. Early laparoscopic intraoperative biliary leak rates reached $26-36 \%$ [2-4] potentially transforming early lesions to T4 disease with major impact on survival: $75 \% 5$ year survival rate in T1a/ T1b to $10 \% 3$ year survival in T4 [5]. Furthermore, early publications on laparoscopic cholecystectomy even for localized disease showed generalized worse outcomes [6].

Adding to the concern was the argument that an initial laparoscopic approaches found to have unexpected, advanced tumors upon entry into the abdomen or gallbladders with concerning appearance (thickened or infiltrated gallbladder walls) would require extended resection $[7,5]$. Thus, these patients would require referral to a center where extended resection could be performed, resulting in treatment delay and potential disease advancement.

Early publications citing port site metastasis in rapid and delayed fashion also raised concern over the laparoscopic approach for gallbladder cancer in any setting [8-10]. Frauenschuh et al. showed that trocar site recurrence occurs in $11-20 \%$ of laparoscopic cases compared to wound recurrence of $3 \%$ in open cases [11]. Additionally, higher abdominal wall recurrence rates have been reported [12]. Initial thinking was that port site recurrence could be avoided by the use of laparoscopic bags, however port site metastasis has been reported in cases where the specimen was collected in a laparoscopic bag and no perforation of the gallbladder occurred during the case. Doudel et al. aimed to explain this phenomenon through the theory that recurrences results from exfoliation of cancer cells into the peritoneum and onto instruments themselves without obvious perforation [13].

For lesions diagnosed preoperatively, concerns are centered on the lack of oncologic minimally invasive surgical experience and potential safety of laparoscopic extended resections (resection of segment IVB and $\mathrm{V}$ or $2 \mathrm{~cm}$ margins around the liver bed and portal lymph node dissection), as well as, the previously described issues above. Multiple publications have shown improved survival in patients with extended resection of gallbladder tumors that have penetrated the muscularis mucosa [14]. Furthermore, Dixon et al. reported findings that patients with all stages of gallbladder cancer, even stage III and IV, have improved survival with $\mathrm{R} 0$ resection; showing an overall 5 year survival improvement from $7 \%$ to $35 \%$ when considering all stages [15]. Along similar lines, Fong et al showed that even for bulky, locally advanced tumors of the liver classified as T3/4, radical resection offered survival advantage [16]. However, other studies suggest that only stage II disease benefits from extended resection [17]. Definitive recommendations are more nuanced in T1b tumors. Glauser et al. reiterated the survival advantage for extended resection in T2/3 tumors, but did not show survival advantage in T1b [18]. Overall, the indication for extended resection of gallbladder carcinoma has grown to encompass tumors previously thought to be unresectable, as well as tumors that were thought to be treated with cholecystectomy alone. An early comparative study showed that of patients with T2 or T3 disease, 5 year survival rate for laparoscopic cholecystectomy alone was $0 \%$ compared to $63 \%$ for patients that were converted to open extended surgery. These findings provided showed the need for R0 resection and raised concerns over the safety of laparoscopic cholecystectomy for gallbladder cancer [6].

Along similar lines, it has become more apparent that even gallbladder cancers confined to the gallbladder wall may have the potential for nodal metastasis. Without lymph node dissection, these tumors have the potential to be inaccurately down-staged. Yokomizo et al. showed the benefit of extended excision and lymph node dissection in patients with $\mathrm{T} 2$ tumors. Of 18 patients empirically treated with radical resection and lymph node dissection, 2 were shown to have lymph node metastasis. Over 27 months, these patients had no recurrences and exhibited an improved overall survival of $87 \%$ in T2NO and $54 \%$ in T2N1 [19]. More evidence was provided for the necessity of lymph

*Corresponding author: Aaron Daniel Pinnola, Department of Surgery, Grand Strand Medical Center, 809 82nd Parkway Myrtle Beach, SC 29572, USA, Tel: 267266-9359; Fax: 843-692-1122; E-mail: aaron.pinnola@hcahealthcare.com

Received October 12, 2015; Accepted December 7, 2015; Published December 14 2015

Citation: Pinnola AD, Hanna N, Boutros C (2015) The Role of Minimally Invasive Surgery in Gallbladder Carcinoma, is it Time to Change our Approach?. Surgery Curr Res 6: 254. doi:10.4172/2161-1076.1000254

Copyright: (c) 2015 Pinnola AD. This is an open-access article distributed under the terms of the Creative Commons Attribution License, which permits unrestricted use, distribution, and reproduction in any medium, provided the original author and source are credited. 
node dissection in T2 as Gourgiotis et al showed that $39-54 \%$ of T2 lesions had lymph node metastasis [20]. Furthermore, other studies have shown that nearly $20 \%$ of T $1 \mathrm{~b}$ tumors had lymph node metastasis [21]. Shibata et al. went to show that among the independent predictors of poor survival: T3 staging, R1 resection and lymphatic invasion; lymphatic invasion had by far the highest disease-specific survival hazard ratio of 5.97 compared to 2.33 for $\mathrm{T} 3$ and 3.17 for $\mathrm{R} 1$ resection [22]. These findings argue that lymphatic invasion may be the best predictor for malignant phenotype and further showing the need for lymph node dissection in lower T rated tumors. These reports predated publications of feasibility of laparoscopic lymph node dissections and thus called into question the appropriateness of laparoscopic surgery in any tumor greater than T1a.

In summary, current recommendations for surgical management of gallbladder cancer are that initial cholecystectomy is adequate for $\mathrm{T} 1 \mathrm{a}$, questionable for $\mathrm{T} 1 \mathrm{~b}$, and extended cholecystectomy should be offered for T2 lesions. Occasionally there is also an indication for radical cholecystectomy with resection of adjacent organs in T4 lesions. As previously outlined the role of laparoscopy is limited secondary to technical ability and risk of tumor dissemination associated with laparoscopy [23].

\section{The data supporting a laparoscopic approach}

As laparoscopic cholecystectomy became more common in practice, retrospective studies on incidentally found gallbladder cancer countered early apprehension for the laparoscopic approach. To date, the largest series published on laparoscopic cholecystectomy for gallbladder carcinoma is Ouchi et al. who detailed 498 patients. In this retrospective series from Japanese cancer registry, patients with $\mathrm{T} 2$ and greater disease were subjected to interval extended excision in an open manner, while T2 or less were treated with laparoscopic cholecystectomy. 5-year survival rates were shown to be $99 \%$ for T1a, $95 \%$ for $\mathrm{T} 1 \mathrm{~b}, 70 \%$ for $\mathrm{T} 2,20 \%$ for $\mathrm{T} 3$, and $0 \%$ for $\mathrm{T} 4$. When these results are compared to results of open approach (100\% for T1a, $75 \%$ for $\mathrm{T} 1 \mathrm{~b}$, $87 \%$ for $\mathrm{T} 2,17 \%$ for $\mathrm{T} 3$, and $0 \%$ for T4), laparoscopic cholecystectomy did not result in worse survival in T1 and T2 lesions. In fact, clinically significant improved survival rates were documented in T1a and T2b [24]. These findings were reiterated by subsequent studies who did not find that laparoscopic approach worsened survival [25], particularly in T1 and in situ disease [26]. Additionally, Ouchi et al. showed that open interval extended resection did not affect disease progression or survival. Subsequent publications also show that interval, definitive resection at a later time in these cases did not affect survival [17].

Western studies, although less powered, echo the results of the Japanese findings. Gumbs et al showed no morbidity or mortality at 3 months for 3 patients with T2 disease who underwent laparoscopic radical resections. Liver margins of 3-5 $\mathrm{cm}$ were achieved, exceeding the accepted margins for open surgery [27]. Clearly, larger reports are indicated, but initial results have been encouraging for the safety of this technique.

Though beyond the scope of this report, robotic hepatobilairy surgery is an evolving subject. It may offer a minimally invasive alternative for surgeons not comfortable with advanced laparoscopic skills. Shen et al has even described a series of 5 patients treated with radical resection robotically. No conversions to open or intraoperative complications were reported [28].

As discussed in the previous section, portal lymph node dissection is now indicated for lesions as low as T1b. Initial reports on laparoscopic radical resection have also detailed the safety of lymph node dissection.
Gumbs et al was able to sample an average of 6 lymph nodes in their reports and adequately stage node status [29]. In a limited study, adequate lymph node sampling was also reported in a robotic approach [28]. Similar to laparoscopic radical resection, the efficacy of laparoscopic lymph node dissection for gallbladder cancer requires larger scale reports, but initial findings are highly encouraging.

Finally, there have been multiple publications arguing that port site metastasis from early stage disease in gallbladder and other cancer has been a myth. Ouchi et al. did find a $20 \%$ perforation rate that was unrelated to depth of invasion and a higher rate of port site metastasis in patients with perforated gallbladders as opposed to nonperforated [24]. However, it remains to be proven that the same mechanism could not happen in open surgery. Lundberg et al reported that while laparoscopic cholecystectomy had a higher rate of port site metastasis than open, open cholecystectomy did result in $6.5 \%$ instance of incisional recurrence [30]. Fuks et al. has shown that port site excision offers no survival advantage in incidentally found gallbladder cancer [31]. Additionally, recent studies have shown that it is associated with already existing peritoneal deposits or distant metastasis [32]. It is clear that peritoneal metastasis at the site of the port is a result of aggressive tumor biology rather than a technical failure. Subsequently, the necessity of port site excision has been debated [33].

\section{Advantages of laparoscopy}

Staging laparoscopy has been shown to clearly identify patients with certain unresectable gallbladder cancers, thus saving patients the morbidity of unnecessary laparotomy, as well as expediting initiation of chemotherapy and radiation therapy. Goere et al. showed that for liver metastasis and peritoneal seeding staging laparoscopy could find $62 \%$ of lesions with $83 \%$ accuracy. However, staging laparoscopy was unable to find vascular invasion and distant metastasis in any of the cases. Overall, staging laparoscopy was able to avoid laparotomy in $36 \%$ of patients who were initially candidates based on imaging [34]. Other studies have found this yield to be as high as 43\% [35]. More recent studies have shown staging laparoscopy to find $94.1 \%$ of unresectable tumors secondary to liver metastasis or peritoneal deposits [36].

With the advent and utilization of laparoscopic ultrasound, staging laparoscopy has become even more effective at improving the accuracy of preoperative staging. Nadeem et al. was able to find $18 \%$ of locally advanced disease initially unvisualized, and went on to prove that implementation of this technique is cost effective as well [37]. Furthermore, in patients with tumors of T2 or less, the combined modalities of laparoscopic ultrasound, computed topography, and endoscopic ultrasound are able to rule out liver metastasis at rate approaching $100 \%$ [38]. Staging laparoscopy has a clear indication for accurately staging gallbladder cancer found on preoperative imaging. Opportunity remains for improvement in this technique, along with other preoperative imaging modalities, to find distant metastasis and vascular invasion.

In addition to the above advantages discussed laparoscopy offers all of the benefits implicit in laparoscopic surgery. The entire abdominal cavity is easily visualized as opposed to what can be visualized through a subcostal incision and the classic beneficial triad of less blood loss, length of stay and early recovery has been documented for laparoscopic cholecystectomy compared to open. McMahon et al. showed that laparoscopic compared to open cholecystectomy resulted in hospital stay was reduced by 2 days and patients returned work sooner. The complication rate was identical at $20 \%$ [39]. Other studies have gone on to show that, as a result of these factors, laparoscopic cholecystectomy 
results in reduction of hospital costs [40]. Considering these advantages, the ability to perform a R0 resection or complete lymph node dissection laparoscopically should nevertheless remain at the forefront of decision making.

\section{Conclusions}

The majority of gallbladder cancers are found incidentally after simple laparoscopic cholecystectomy by surgeons not specialized in hepatobiliary surgery or surgical oncology. For in situ and T1a lesions, this procedure is adequate and no further intervention is needed. Extended resection for T1b lesions is debatable. If a gallbladder is found to have appearance concerning for malignancy, obvious advanced disease is present, or disease is found preoperatively, referral is a specialized center for extended resection is indicated. As the field of laparoscopy has advanced, extended laparoscopic resections are now possible for the majority of surgically treated lesions. However, excision of T2-4 lesions and portal lymph node dissection laparoscopically should be treated on an individual basis considering the surgeon's technical ability, specific features of the lesion, and confidence in performing a R0 resection. Prospective studies on this matter would provide further clarity.

\section{References}

1. Boutros C, Gary M, Baldwin K, Somasundar P (2012) Gallbladder cancer: past, present and an uncertain future. Surg Oncol 21: 183-191.

2. Kimura T, Goto H, Takeuchi Y, Yoshida M, Kobayashi T, et al. (1996) Intraabdominal contamination after gallbladder perforation during laparoscopic cholecystectomy and its complications. Surg Endosc 10: 888-891.

3. Jones DB, Dunnegan DL, Soper NJ (1995) The influence of intraoperative gallbladder perforation on long-term outcome after laparoscopic cholecystectomy. Surg Endosc 9: 977-980.

4. Hui TT, Giurgiu DI, Margulies DR, Takagi S, lida A, et al. (1999) latrogenic gallbladder perforation during laparoscopic cholecystectomy: etiology and sequelae. Am Surg 65: 944-948 .

5. Weiland ST, Mahvi DM, Niederhuber JE, Heisey DM, Chicks DS, et al. (2002) Should suspected early gallbladder cancer be treated laparoscopically?. J Gastrointest Surg 6: 50-56.

6. Yoshida T, Matsumoto T, Sasaki A, Morii Y, Ishio T, et al (2000) Laparoscopic cholecystectomy in the treatment of patients with gall bladder cancer. J Am Coll Surg 191: 158-163

7. Wysocki A, Bobrzynski A, Krzywon J, Budzynski A (1999) Laparoscopic cholecystectomy and gallbladder cancer. Surg Endosc 13: 899-901.

8. Sultania M, Pandey D, Sharma J, Mallick S, Mridha AR (2014) Delayed Isolated Port-Site Metastasis of Gallbladder Cancer Following Laparoscopic Cholecystectomy: Report of Two Cases. J Gastrointest Cancer 45: 188-191.

9. Fong Y, Jarnagin W, Blumgart LH (2000) Gallbladder cancer: comparison of patients presenting initially for definitive operation with those presenting after prior noncurative intervention. Ann Surg 232: 557-569.

10. Reddy YP, Sheridan WG (2000) Port-site metastasis following laparoscopic cholecystectomy: a review of the literature and a case report. Eur J Surg Oncol 26: 95-98.

11. Frauenschuh D, Greim R, Kraas E (2000) How to proceed in patients with carcinoma detected after laparoscopic cholecystectomy. Langenbecks Arch Surg 385: 495-500.

12. Suzuki K, Kimura T, Ogawa H (1998) Is laparoscopic cholecystectomy hazardous for gallbladder cancer? . Surgery123: 311-314

13. Doudle M, King G, Thomas WM, Hewett P (1996) The movement of mucosal cells of the gallbladder within the peritoneal cavity during laparoscopic cholecystectomy. Surg Endosc10: 1092-1094.

14. Steinert R, Nestler G, Sagynaliev E, Müller J, Lippert H, et al. (2006) Laparoscopic cholecystectomy and gallbladder cancer. J Surg Oncol 93: 682689 .
15. Dixon E, Vollmer CM Jr, Sahajpal A, Cattral M, Grant D, et al. (2005) An aggressive surgical approach leads to improved survival in patients with gallbladder cancer: a 12-year study at a North American Center. Ann Surg 241 385-394.

16. Nasiri S, Gafuri A, Karamnejad M, Farshidfar F (2009) Four port-site recurrences of gall bladder cancer after laparoscopic cholecystectomy. ANZ J Surg 79: 75-76.

17. Shih SP1, Schulick RD, Cameron JL, Lillemoe KD, Pitt HA, et al. (2007) Gallbladder cancer: the role of laparoscopy and radical resection. Ann Surg 245: 893-901.

18. Glauser PM, Strub D, Käser SA, Mattiello D, Rieben F, et al. (2010) Incidence, management, and outcome of incidental gallbladder carcinoma: analysis of the database of the Swiss association of laparoscopic and thoracoscopic surgery. Surg Endosc 24: 2281-2286.

19. Yokomizo H, Yamane T, Hirata T, Hifumi M, Kawaguchi T, et al. (2007) Surgical treatment of pT2 gallbladder carcinoma: a reevaluation of the therapeutic effect of hepatectomy and extrahepatic bile duct resection based on the long-term outcome. Ann Surg Oncol14: 1366-1373.

20. Gourgiotis S, Kocher HM, Solaini L, Yarollahi A, Tsiambas E, et al. (2008) Gallbladder cancer. Am J Surg 196: 252- 264.

21. Fetzner UK, Hölscher AH, Stippel, DL (2011) Regional lymphadenectomy strongly recommended in T1b gallbladder cancer. World J Gastroenterol 17 4347-4348.

22. Shibata K, Uchida H, Iwaki K, Kai S, Ohta M, et al. (2009) Lymphatic invasion an important prognostic factor for stages T1b-T3 gallbladder cancer and an indication for additional radical resection of incidental gallbladder cancer. World J Surg 33: 1035-1041.

23. Chiche L, Metairie S (2001) Fortuitous discovery of gallbladder cancer. J Chir (Paris) 138: 336-341.

24. Ouchi K, Mikuni J, Kakugawa Y (2002) Laparoscopic cholecystectomy for gallbladder carcinoma: results of a Japanese survey of 498 patients. J Hepatobiliary Pancreat Surg 9: 256-260.

25. Whalen GF, Bird I, Tanski W, Russell JC, Clive J (2001) Laparoscopic cholecystectomy does not demonstrably decrease survival of patients with serendipitously treated gallbladder cancer. J Am Coll Surg 192: 189-195.

26. Yamaguchi K, Chijiiwa K, Ichimiya H, Sada M, Kawakami K, et al. (1996) Gallbladder carcinoma in the era of laparoscopic cholecystectomy. Arch Surg 131: $981-984$

27. Gumbs AA, Hoffman JP (2010) Laparoscopic completion radical cholecystectomy for T2 gallbladder cancer. Surg Endosc 24: 3221-3223.

28. Shen BY, Zhan Q, Deng XX, Bo H, Liu Q, et al. (2012) Radical resection of gallbladder cancer: could it be robotic?. Surg Endosc 26: 3245-3450.

29. Gumbs AA, Hoffman JP (2010) Laparoscopic radical cholecystectomy and Roux-en-Y choledochojejunostomy for gallbladder cancer. Surg Endosc 24 1766-1768.

30. Lundberg O, Kristoffersson A (2001) Open versus laparoscopic cholecystectomy for gallbladder carcinoma. J Hepatobiliary Pancreat Surg 8: 525-529.

31. Fuks D, Regimbeau JM, Pessaux P, Bachellier P, Raventos A, et al. (2013) Is port-site resection necessary in the surgical management of gallbladder cancer?. J Visc Surg 150: 277-284

32. Z'graggen K, Birrer S, Maurer CA, Wehrli H, Klaiber C, et al. (1998) Incidence of port site recurrence after laparoscopic cholecystectomy for preoperatively unsuspected gallbladder carcinoma. Surgery 124: 831-838.

33. Maker AV, Butte JM, Oxenberg J, Kuk D, Gonen M, (2012) Is port site resection necessary in the surgical management of gallbladder cancer?. Ann Surg Oncol 19: 409-417.

34. Goere D, Wagholikar GD, Pessaux P, Carrère N, Sibert A, et al. (2006) Utility of staging laparoscopy in subsets of biliary cancers : laparoscopy is a powerful diagnostic tool in patients with intrahepatic and gallbladder carcinoma. Surg Endosc 20: 721-725.

35. Weber SM, DeMatteo RP, Fong Y, Blumgart LH, Jarnagin WR (2002) Staging laparoscopy in patients with extrahepatic biliary carcinoma. Analysis of 100 patients. Ann Surg 235: 392-399.

36. Agarwal AK, Kalayarasan R, Javed A, Gupta N, Nag HH (2013) The role 
Citation: Pinnola AD, Hanna N, Boutros C (2015) The Role of Minimally Invasive Surgery in Gallbladder Carcinoma, is it Time to Change our Approach?. Surgery Curr Res 6: 254. doi:10.4172/2161-1076.1000254

of staging laparoscopy in primary gall bladder cancer--an analysis of 409 patients: a prospective study to evaluate the role of staging laparoscopy in the management of gallbladder cancer. Ann Surg 258: 318-323.

37. Nadeem H, Jayakrishnan TT, Groeschl RT, Zacharias A, Clark Gamblin T, et al. (2014) Cost effectiveness of routine laparoscopic ultrasound for assessment of resectability of gallbladder cancer. Ann Surg Oncol 21: 2413-2419.
38. Cho JY, Han HS, Yoon YS, Ahn KS, Kim YH, et al. (2010) Laparoscopic approach for suspected early-stage gallbladder carcinoma. Arch Surg 145: 128-133.

39. McMahon AJ1, Russell IT, Baxter JN, Ross S, Anderson JR, et al. (1994) Laparoscopic versus minilaparotomy cholecystectomy: a randomised trial. Lancet 343: 135-138.

40. Gadacz TR1, Talamini MA (1991) Traditional versus laparoscopic cholecystectomy. Am J Surg 161: 336-338. 